\title{
Post dural puncture headache
}

\author{
J Singh, ${ }_{1}^{1}$ S Ranjit, ${ }^{1}$ S Shrestha, ${ }^{1}$ T Limbu, ${ }^{2}$ S. B. Marahatta ${ }^{3}$ \\ ${ }^{1}$ Department of Anaesthesia, Kathmandu University School of Medical Sciences Dhulikhel Kavre, Nepal; ${ }^{2}$ KUSMS \\ Dhulikhel Kavre, Nepal; ${ }^{3}$ Department of Community Medicine, Kathmandu University School of Medical Sciences, \\ KUSMS Dhulikhel Kavre, Nepal.
}

Correspondence to: Dr. Jeevan Singh, Department of Anaesthesia, Kathmandu University School of Medical Sciences, Dhulikhel Kavre, Nepal. Mobile: 985102993

Email:docjeevan@yahoo.co.in

\begin{abstract}
Introduction: Post dural puncture headache occurs as the cerebrospinal fluid leaks out from the breach that the needle has made in the dura. The incidence of Post Dural Puncture Headache (PDPH) is a common complication after spinal anesthesia. The objective of our study is to find out incidence of PDPH in patients undergoing surgery under spinal anesthesia in Dhulikhel Hospital.

Methods: 120 patients who underwent spinal anesthesia were selected for the study. Questionnaire was used to assess the post dural puncture headache 24 hours after surgery. Headache, if present in frontal or occipital areas which increased when sitting or situational movement and relieves by lying in flat position were considered as PDPH.

Results: PDPH was observed in $25 \%$ of the patients. The incidence of PDPH is $30 \%$ and $70 \%$ in male and female respectively. It was 2.33 times more in age group 18-30-years than 31-45 years.

Conclusions: The incidence of PDPH was high in female and age group 18-30 years. The incidence of PDPH is high when the bevel is transverse to the dural fibers.
\end{abstract}

Keywords: Bevel direction, incidence, post-dural puncture headache, spinal anesthesia

\section{Introduction}

Subarachnoid blockade (SAB) or spinal anesthesia has been the standard method for many years for surgery below umbilicus in a fit patient. Since the introduction of spinal anesthesia, headache has remained a well recognized complication. ${ }^{1}$ Post dural puncture headache occurs as the cerebrospinal fluid leaks out from the breach that the needle has made in the dura. ${ }^{2}$ The physical phenomenon which causes spinal headache is explained as when the needle pierces durameter and cerebrospinal fluid can leak out and pressure drops. The cushioning effect of the fluid disappears and tension is applied directly to the cranial nerves. The onset of post dural puncture headache varies from 24 hours to seven days. ${ }^{3}$ Ninety percent of post dural puncture headache occurs within 3 days of the procedure and $66 \%$ starts within 48 hours. ${ }^{4}$ Repeated dural puncture significantly increases the incidence of post dural puncture headache. Use of small gauze needle has been demonstrated to decrease the incidence of post dural puncture headache. ${ }^{5}$

Patient dependent factors - age, gender and technical features like diameter of the needle have been implicated in influencing the risk of developing post dural puncture headache. ${ }^{6}$ Every month around $60-70$ surgeries are performed under spinal anesthesia in Dhulikhel hospital. Majority of PDPH resolves spontaneously and in some cases it lasts for months or even years. Identifying the incidence and risk of post dural puncture headache in the patients might be useful in preventing the complications.

\section{Methods}

The study was cross sectional design carried out among 120 patients who underwent surgery under spinal anesthesia at Dhulikhel Hospital, KUTH, Dhulikhel, Kavre. The patients of age group 18-45 years who underwent 
surgery under spinal anesthesia in Dhulikhel Hospital during June 2008 till August 2008 were enrolled in the study. Patients with ASA grade III or more, previous history of migraine, hypertension, neurological diseases, history of fever, common cold, sinusitis, features of raised intracranial pressure were excluded from the study.

Written informed consent was taken from the subjects and interview was taken 24 hours after giving spinal anesthesia. The data were coded and entered into SPSS and was analyzed using the standard chi-square.

\section{Results}

The mean age of the respondents was $35.03 \pm 9.66$ years, weight $53.89 \pm 8.02 \mathrm{~kg}$, height $1.55 \pm 0.09 \mathrm{~m}$, BMI $22.39 \pm 2.99$ $\mathrm{kg} / \mathrm{m}^{2}$ in the study. The male: female ratio was $1.1: 1$. The incidence of post dural puncture headache was $25 \%$. The incidence of PDPH was $30 \%$ and $70 \%$ in male and female respectively ( $\mathrm{p}=0.100)$. Among 120 respondents, 45 were from age group 18-30 among which 70\% experienced post dural puncture headache whereas 75 were from age group $31-45$ among which $30 \%$ of them had post dural puncture headache (Fig. 1). The chi- square test was used to show the association between the post dural puncture headache and age group. The p-value was 0.014 which was lesser than 0.05 and the association of incidence of PDPH with age group was statistically significant at 5\% level. In obstetrics and gynaecological patients, 50\% experienced post dural puncture headache (Table 1) $(\mathrm{p}=0.043)$, hence, the association was statistically significant. The incidence of PDPH was 50\% when the bevel was transverse to dural fibres (Table 2). $80 \%$ of patient who experienced post dural puncture headache had onset of PDPH within 24 hours of surgery. Dull pain was seen in $80 \%$ of patients among those experiencing post dural puncture headache and $80 \%$ of patient experiencing post dural puncture headache had pain on the frontal region (Fig. 2).

\section{Discussion}

As per our findings, the incidence of PDPH was 25\%. There is considerable evidence that the PDPH is due to low CSF pressure consequent upon seepage of CSF through the dural puncture hole and choroid plexus is unable to secrete sufficient fluid to maintain the CSF pressure. Moreover the negative pressure in the epidural space may draw CSF from subarachnoid space CSF leakage from the dural hole produces CSF hypotension which in turn leads to intracranial venous dilation resulting in an increase in brain volume in the upright position. There occurs a difference in CSF volume and also pressure differential between the intracranial and intravertebral part of the subarachnoid space. Venous dilation and compensatory increase in brain volume will result in brain sag which in turn will exert traction and stimulate pain sensitive anchoring structures like dural vessels, basal dura and tentorium cerebelli, causing post spinal headache. Larger the hole in dura mater more will be the leakage of CSF and longer the time required for repair. The number of holes in dura also makes a difference in the loss of CSF. The overall incidence of post spinal headache has varied from 0 to $78 \%$, as reported by authors. ${ }^{7}$ The most important factors for contributing to the higher incidence of PDPH were age, sex of the respondents and the direction of the bevel.

The limitation of this study was small size of the group. The observed incidence of PDPH in our study was in accordance with the above finding. The incidence of PDPH was $30 \%$ and $70 \%$ in male and female respectively. The difference was statistically not significant. The finding of present study is consistent with the study done by Evans RW et al., in America concluded that PDPH occurs twice as often as in men, ${ }^{8}$ which in our study, $60 \%$ of patients experienced PDPH who had undergone obstetrical/gynae surgery. The result was consistent with the study done in America which concluded the incidence of PDPH to be $18 \%$ and $13 \%$ in obstetrical and non obstetrical patients respectively. ${ }^{8}$ Several literatures suggested that the parturient are at particular risk of dural puncture and the subsequent headache because of their sex, young age, and the widespread application of epidural anesthesia. The incidence of PDPH is more common among parturient because of reduction of both the intra abdominal and epidural pressure after delivery, thereby promoting more leakage of CSF than usual. The factors contributing for an increased incidence of PDPH in obstetric patient also include stress of labor, changing hormonal level and dehydration. ${ }^{1}$

In the present study, the incidence of PDPH was $70 \%$ in age group $18-30$ and $30 \%$ in $31-45$ which is consistent with the result of a study by Choi $\mathrm{PT}$ which concluded that the incidence of PDPH was $65 \%$ in $18-30$ years old age group. ${ }^{3}$ With the bevel direction upward, 50\% had incidence of PDPH which is similar to study done by Flatten $\mathrm{H}$. et al which concluded the incidence of PDPH was $22.6 \%$ and $3.8 \%$ in transverse and parallel group. ${ }^{9}$ The study done by Feron $\mathrm{W}$, concluded that PDPH occurs more often in young adults, who are affected four times more often than patients aged 60 to 69 years. ${ }^{5}$ The lower incidence among older people has been suggested to arise from a decrease in elasticity of pain sensitive structures secondary to atherosclerosis, or from age related mechanical changes in the epidural space.

In the present study, the incidence of PDPH was equal in both groups who were preloaded and without preload. 
Similarly incidence of PDPH was equal in patients who followed and did not follow instruction to lie in supine position for $24 \mathrm{hrs}$ post dural puncture. This result was consistent with the result of a study by Sudlow C et al., which revealed the role of fluid supplementation in the prevention of PDPH is uncertain and also concluded that there is no good evidence that routine bed rest after dural puncture is beneficial. ${ }^{11}$

A study by Shah A et al., concluded that 8 out of 9 had headache on the frontal region whereas in the present study $80 \%(8 / 10)$ had dragging type of pain located on frontal region. ${ }^{1}$ In the present study the onset of headache was within $24 \mathrm{hrs}$ in $80 \%$ of patients. The result is consistent with the study by Turnbull D et al where $90 \%$ of patient had headache within 3 days of the procedure, $66 \%$ started within $1^{\text {st }} 48 \mathrm{hrs} .{ }^{12}$ Lomox $\mathrm{S}$ found the onset of headache as early as 20 minutes. ${ }^{13}$

\section{Conclusions}

The incidence of PDPH is high among young age and obstetric patients. Since half of the patients experienced PDPH when the bevel was transverse to dural fibres, the bevel direction transverse to the dural fibers appears to contribute to increased incidence of PDPH. Bed rest and preload fluid did not provide evidence of decreasing the incidence of PDPH.

\section{References}

1. Shah A, Bhatia P, Tulsiani KL. PDPH- in cesarean section-a comparative study using $25 \mathrm{~g}, 27 \mathrm{~g}$ quincke and $27 \mathrm{~g}$ whitacre needle. Indian Journal of Anesthesia 2002;4(6):373-7.

2. Ayim, E, Bewis PE. Primary anesthesia. $7^{\text {th }}$ ed. Oxford University; 2006. p . 54-6.

3. Choi PT. PDPH is a common complication of neuroaxial blockade in parturients: a meta-analysis of obstetrical studies. Canadian Journal of Anesthesia; 2003;50:460-9.

4. Turnbull DK, Shepherd DB. Post-dural puncture headache:pathogenesis, prevention and treatment. British Journal of Anesthesia 2003;91(5):718-29.

5. Fearon W. Post- lumbar puncture headache. p\& s medical review 1994;1(2):1-6.

6. Gosch UW, Hueppe M, Hallschmid M, Born J, Schmucker P, Meier T. Post dural puncture headache in young adults: comparison of two small- gauge spinal catheters with different needle design. British
Journal of Anesthesia 2005; 94(5):657-661.

7. Mohammadzadeh JA, Haghighi M, Naderi N B. Incidence of post dural puncture headache in patients undergoing cesarean section in alzahare hospital. Canadian Journal of Anesthesia 2005; 49(2):506-508.

8. Evans RW, Arman C, Frohman E M, Grodin DS. Assessment: Prevention of Post Lumbar Puncture Headache. American Academy Of Neurology 2000;55:909-14.

9. Flatten, $\mathrm{H}$, et al. Puncture technique and postural post dural puncture headache-A randomized, double blind study comparing transverse and parallel puncture. British Journal of Anesthesia 1999; 43(9): 967-968.

10. Seeberger, M.D., Kaufmann, M., Staender, S., Schneider, M., and Scheidegger, D. Repeated Dural Punctures Increases The Incidence of Postdural Puncture Headache. Anesthesia and analgesia 2002;82:302-305.

11. Sudlow C, Warlow C. Posture and fluids for preventing post- dural puncture headache. The Cochraine Database of Systematic Review. 2002;42:11-5.

12. Turnbull, DK, shepherd DB. Post-dural puncture headache: pathogenesis, prevention and treatment. British journal of anesthesia. 2003;91(5):718-29.

13. Lomax S, Quereshi. Unusually early onset of postdural puncture headache after spinal anesthesia using a $27 \mathrm{~g}$ whittacre needle. British Journal of Anesthesia, 2008;100(5):707-8. 